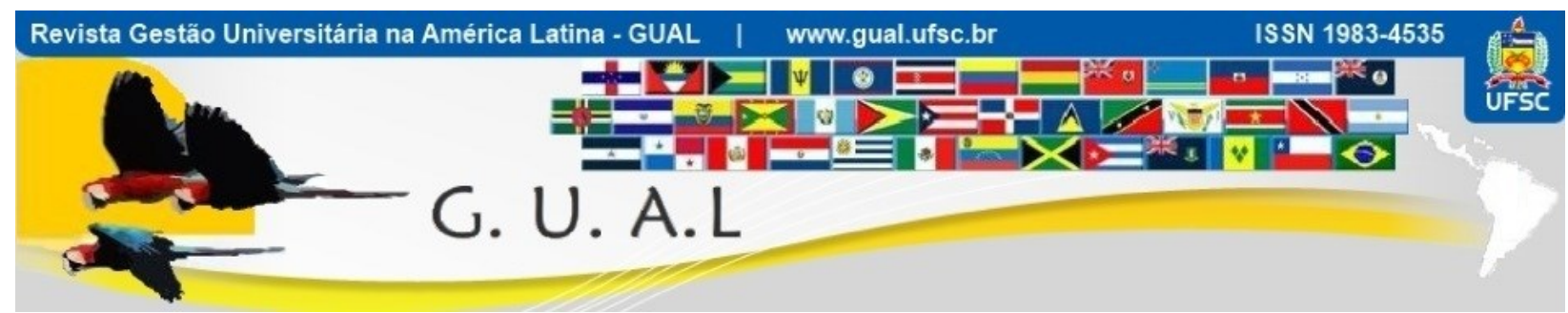

DOI: http://dx.doi.org/10.5007/1983-4535.2015v8n3p281

\title{
METODOLOGIAS DE ENSINO-APRENDIZAGEM: UMA ABORDAGEM SOB A PERCEPÇÃO DOS ALUNOS
}

\section{METHODS OF TEACHING-LEARNING APPROACH IN THE PERCEPTION OF STUDENTS}

Josiane Brighenti, Mestre

Universidade Regional de Blumenau - FURB josianebrighenti@gmail.com

Vania Tanira Biavatti, Doutora Universidade Regional de Blumenau - FURB vania@hprada.com.br

Taciana Rodrigues de Souza, Mestre Universidade Regional de Blumenau - FURB taciana.rodrigues.souza@gmail.com

Recebido em 23/julho/2014

Aprovado em 26/junho/2015

Sistema de Avaliação: Double Blind Review

Esta obra está sob uma Licença Creative Commons Atribuição-Uso. 


\title{
RESUMO
}

O objetivo do estudo consiste em verificar quais os métodos de ensino se mostram mais eficazes em relação à aprendizagem, na percepção dos alunos e, destes, quais têm sido mais utilizados pelos professores. Metodologicamente a pesquisa caracteriza-se como descritiva quanto ao objetivo, de levantamento em relação aos procedimentos e quantitativa quanto ao tratamento e análise dos dados. A população do estudo compreendeu os alunos e professores do Curso de Ciências Contábeis da Universidade Comunitária da Região de Chapecó em Santa Catarina, com uma amostra composta por amostra 95 alunos e 17 professores. Como resultados verificou-se que, na percepção dos alunos, o método e técnica de ensino considerado mais eficaz para o aprendizado é a resolução de exercício, porém, a aula expositiva (teórica) é a metodologia mais utilizada pelos professores. Quanto a importância e eficiência dos recursos para o aprendizado, a utilização de livros e apostilas o mais indicado pelos alunos, no entanto, o PowerPoint (data show) é o recurso mais utilizado pelos professores. Desta forma, concluiu-se que não houve uma convergência do que os alunos consideram eficaz para seu aprendizado, com o que na percepção deles os professores têm mais utilizado para o ensino.

Palavras-chave: Aprendizagem. Saberes Docentes. Métodos e metodologias de ensino. Percepção.

\begin{abstract}
The objective of the study is to determine which teaching methods are most effective in relation to learning in the perception of students and of those which have been most used by teachers. Methodological research is characterized as descriptive as the goal, lifting with regard to procedures and quantitative regarding the processing and analysis of data. The study population comprised students and teachers of Accounting Course Community of the Region of Chapecó University of Santa Catarina, with a sample of sample 95 students and 17 teachers. As a result it was found that, in the perception of the students, the teaching method and technique considered more effective for learning is solving exercise, however, the lecture (theory) is a methodology widely used by teachers. As the importance and efficiency of resources for learning, the use of books and handouts as indicated by the students, however, PowerPoint (data show) is the tool most used by teachers. Thus, it was concluded that there was a convergence of what students consider effective for their learning, with what in their perception teachers have used more for teaching.
\end{abstract}

Keywords: Learning. Teachers knowledge. Methods and teaching methodologies. Perception. 


\section{INTRODUÇÃO}

A educação, bem como o processo educativo, deve ser orientada por metodologias que permitam atender aos objetivos propostos pelos docentes. Conforme Nérice (1978, p.284), a metodologia do ensino pode ser compreendida como um "conjunto de procedimentos didáticos, representados por seus métodos e técnicas de ensino", esse conjunto de métodos são utilizados com o intuito de alcançar objetivos do ensino e de aprendizagem, com a máxima eficácia e, por sua vez, obter o máximo de rendimento.

As mudanças que ocorreram na forma de ensino com o uso das tecnologias, os desafios impostos aos professores e as oportunidades com a inserção de novas formas e meios, exige dos professores novos métodos de ensino. Volta-se a atenção para as transformações da sociedade e a necessidade de modificar as tradicionais formas de ensinar, de aprimorar constantemente as práticas e os saberes docentes (VAILLANT; MARCELO, 2012).

As discuções acerca dos saberes docentes têm se intensificado nas últimas décadas, e tornou-se objeto de pesquisas em todo o mundo. Tais estudos surgiram como consequência à profissionalização do ensino e dos docentes, e remetem ao fato destes saberes não se limitarem à transmissão de conhecimento aos alunos, mas sim a um conjunto de fatores que são construídos e adquiridos com a formação e a experiência, vivências e habilidades específicas adquiridas com o tempo (CUNHA, 2007; TARDIF, LESSARD, LAHAYE, 1991).

Conforme o entendimento de Tardif (2002), os saberes docentes são adquiridos e construídos em um processo contínuo de aprendizagem, em que o professor aprende de forma progressiva e, com isso, se insere e domina seu ambiente de trabalho. Assim, não se pode dizer que os saberes docentes são constituídos por um conjunto de conteúdo definidos e imutáveis.

Os estudos relacionados à formação e profissão docente, orientam para a necessidade de uma revisão da compreensão das práticas pedagógicas dos professores. Com isso, considera-se que o docente em sua trajetória profissional, constrói e reafirma seus conhecimentos, levando em conta a necessidade de sua utilização, suas experiências, e seu percurso na formação (NUNES, 2001).

Anastasiou (2001), faz um resgate histórico dos métodos e metodologias de ensino, e revela que as escolas jesuítas influenciaram por muito tempo, a forma de ensino no Brasil com reflexos que permanecem até hoje. Aulas expositivas, resolução de exercicios, 
memorização de conteúdos, e um sistema rígido de conduta e avaliação eram características comuns do sistema jesuítico.

Na concepção de Veiga (2006), o professor não pode mais ser aquele que tem uma didática definida com papel de apenas ensinar o conteúdo, ele deve assumir seu papel de mentor e facilitador, deve priorizar e intermediar o acesso do aluno à informação. Com isso, suas técnicas devem ser aprimoradas constantemente e seus métodos e metodologias de ensino, consequentemente, atender às necessidades que vão surgindo.

Diante deste contexto, expõem-se a questão norteadora deste estudo: quais os métodos de ensino são mais eficazes em relação à aprendizagem e, destes, quais têm sido mais utilizados pelos professores na percepção dos alunos? Desta forma, o objetivo consiste em verificar quais os métodos de ensino se mostram mais eficazes em relação à aprendizagem, na percepção dos alunos e, destes, quais têm sido mais utilizados pelos professores. Em complemento ao estudo, também analisa-se a titulação e a formação docente que os professores tiveram ou têm frente aos dados levantados.

O estudo justifica-se pela importância do meio acadêmico conhecer as metodologias de ensino que os alunos consideram mais eficazes para sua aprendizagem e, com base nessas informações melhor gerenciar as atividades de ensino e, se necessário for, revisar a política de ensino adotada. Nesse sentido, os resultados deste estudo visam contribuir e subsidiar decisões de gestão do processo ensino-aprendizagem, tanto do ponto de vista da docência quanto, principalmente, de políticas das instituições de ensino superior.

De acordo com Miranda (2006), a expansão e variedade das Instituições de Ensino Superior, faz com que essas instituições se atentem às práticas de gestão e desenvolvimento de novas estratégias para se sobressair às demais. Entretando, na concepção de Canterle e Favaretto (2008), os desafios impostos às IES são referentes à gestão e a construção da qualidade, em um cenário altamente dinâmico, constituem desafios impulsionando-as para que busquem novas alternativas de gerenciamento e eficiência para fornecer ensino de qualidade à sociedade.

A amostra escolhida para a pesquisa, justifica-se por ser um estágio mais avançado do curso, nesta etapa há menores índices de desistência e, além disso, os alunos já possuem melhor discernimento para elencar quais os métodos mais eficientes para seu aprendizado. A escolha da Instituição de Ensino Superior deu-se pela acessibilidade para aplicação da 
pesquisa, e também pela significância desta IES no âmbito do ensino superior da região que está localizada.

\section{REFERENCIAL TEÓRICO}

Neste tópico são abordados aspectos que fundamentam e referenciam este estudo, para melhor entendimento do tema e objetivo proposto, envolve uma revisão da literatura acerca dos saberes docentes, métodos e metodologias e estudos correlatos.

\subsection{SABERES DOCENTES}

O campo de pesquisa acerca dos saberes docentes é bastante amplo e, nas últimas décadas vem se desenvolvendo de maneira exponencial. Os estudos sobre os saberes docentes surgiram no Brasil a partir da década de 1990, como uma das consequências do movimento pela profissionalização do ensino e, da profissionalização docente (CUNHA, 2007).

Os saberes docentes ou saberes dos professores, têm sido objeto de discussão por parte de um grande número de autores nacionais e internacionais. Neste cenário destaca-se Tardif, Lessard e Lahaye (1991, p.218) demonstrando que "a relação dos docentes com os saberes não se reduz a uma função de transmissão dos conhecimentos já constituídos, (pois) sua prática integra diferentes saberes, com os quais o corpo docente mantém diferentes relações". Desta forma, os autores destacam que para dar conta dos objetivos traçados, os professores comumente utilizam os saberes das disciplinas, os saberes curriculares, os saberes da formação profissional e os saberes da experiência.

Na concepção de Pimenta (1997), os saberes docentes podem ser vistos sob três óticas, a da experiência, do conhecimento e dos saberes pedagógicos. No que diz respeito aos saberes da experiência, são aqueles que o professor em formação traz consigo, relativo à sua experiência e vivências como aluno e em atividades docentes. Além disso, os saberes da experiência envolvem aqueles produzidos no cotidiano docente e, nos processos de reflexão da sua própria prática e de colegas de trabalho.

Quanto aos saberes do conhecimento, Pimenta (1997) salienta que envolve como o professor utiliza o conhecimento adquirido no processo de ensino, e que não se resume na informação obtida, mas sim no poder de trabalhar com esta informação, processá-la, classificá-la, analisá-la e contextualizá-la. 
O terceiro aspecto, é a dos saberes pedagógicos, não bastando apenas experiência e conhecimentos específicos, mas é preciso também saber ensinar, e isso o professor adquire, constrói e aprimora ao longo de sua formação docente com seu próprio fazer (PIMENTA, 1997).

O saber dos professores é construído ao longo de uma carreira profissional, desta forma, não é possível dizer que os saberes docentes são constituídos apenas por um conjunto de conteúdos cognitivos definidos e imutáveis. O saber dos docentes é adquirido e construído em um processo contínuo de aprendizagem, no qual o professor aprende progressivamente, e assim, consequentemente se insere e domina seu ambiente de trabalho (TARDIF, 2002).

Saviani (1996) faz referência aos saberes que devem ser construídos pelos professores em seu processo de formação inicial e continuada, e afirma que sendo o processo educativo um fenômeno complexo, os saberes envolvidos também o são. Conforme o autor, há cinco categorias de saberes, sendo elas o saber atitudinal, o saber crítico-contextual, os saberes específicos, o saber pedagógico e o saber didático curricular e, salienta que são esses os saberes que todo educador deve dominar, e desta forma, devem fazer parte do seu processo de formação.

Gauthier et al. (1998) destaca que os saberes são necessários ao ensino e que juntos formariam uma espécie de "reservatório" para que o professor se abastecesse a fim de responder às exigências específicas de sua situação concreta de ensino. Os autores elencam seis categorias de saberes, sendo elas os saberes disciplinares, os saberes curriculares, os saberes das ciências da educação, os saberes da tradição pedagógica, os saberes experienciais e os saberes da ação pedagógica.

Caldeira (1995), ressaltou a importância de considerar o estudo da prática docente como processo informal, dinâmico, complexo e carregado de valores. Destacou também, que o "valor" do saber produzido por meio da prática cotidiana do professor, é resultante de um processo de reflexão realizado coletivamente a partir das "condições materiais e institucionais" da escola, considerando-se a dimensão histórica e social em que é construída a prática docente.

Quanto a formação do professor, Pimenta (1997) salienta que a atividade do professor não é burocrática, não necessita apenas conhecimentos e habilidades técnicas para cumprir seu papel na sociedade, portanto, na formação destes é necessário desenvolver conhecimentos 
e habilidades, atitudes e valores que possibilitem a construção constante dos saberes docentes, a partir da necessidade e desafios impostos no cotidiano.

Na concepção de Tardif (2002, p.18) o saber envolve além do conhecimento, "saberfazer bastante diverso", provenientes de diversas fontes e de naturezas diferentes, por esse motivo é considerado "plural, compósito, heterogêneo". O autor enfatiza ainda que o "saber está a serviço do trabalho", pois os professores utilizam diferentes saberes em função das condições, situações e recursos ligados a este trabalho, visando enfrentar e solucionar diferentes problemas ou situações em seu cotidiano.

Tardif (2000), considera que os saberes profissionais dos professores são plurais e heterogêneos, e que isso se deve a três fatores. Primeiramente são assim considerados porque provêm de diversas fontes, podem ser oriundos da cultura pessoal do professor, história de vida e experiência escolar anterior, conhecimentos disciplinares adquiridos na universidade, em sua formação profissional. Podem ser também conhecimentos curriculares provenientes de programas, guias e manuais escolares, e principalmente a experiência adquirida com seu trabalho.

Em segundo lugar, os saberes são variados e heterogêneos porque não são unificados, mas sim ecléticos, pois os professores utilizam-se de diferentes teorias, concepções e técnicas, conforme a necessidade encontrada. O terceiro fator se refere ao fato do professor tentar atingir diferentes objetivos em sala de aula, além de ensinar, busca motivar e despertar interesse dos alunos, acompanhar a aprendizagem, dar explicações, fazer com que os alunos compreendam e aprendam, exigindo assim do profissional mais do que o conhecimento, competência ou aptidão, visto que precisam desenvolver outras habilidades de liderança e desenvolvimento de estratégias para atingir seus objetivos (TARDIF, 2000).

Nesse sentido, outra concepção acerca dos saberes docentes é a pluralidade, devido ao fato de envolver diversas teorias, e a temporalidade, pois é adquirido no decorrer da carreira profissional. A ideia de temporalidade supõe o fato de aprender a ensinar com o tempo. O professor aprende os saberes necessários ao trabalho docente, passando por um processo progressivo, iniciado quando ainda está em sala de aula na condição de aluno em formação (TARDIF, 2002).

A fim de melhorar a compreensão e visualização das categorizações dos saberes docentes, apresenta-se no Quadro 1, um resumo esquematizado com as atribuições as contribuições dos principais autores sobre o tema. 


\begin{tabular}{|c|c|c|c|c|}
\hline $\begin{array}{c}\text { Categorias do } \\
\text { saber docente }\end{array}$ & $\begin{array}{c}\text { Tardif, Lessard e } \\
\text { Lahaye (1991) }\end{array}$ & Saviani (1996) & Gauthier et al. (1998) & $\begin{array}{c}\text { Pimenta } \\
\text { (1999) }\end{array}$ \\
\hline Pedagógico & Saberes curriculares; & $\begin{array}{c}\text { Saber didático- } \\
\text { curricular. }\end{array}$ & $\begin{array}{c}\text { Saberes disciplinares; } \\
\text { Saberes da tradição } \\
\text { pedagógica; Saberes da } \\
\text { ação pedagógica. }\end{array}$ & $\begin{array}{c}\text { Saberes } \\
\text { pedagógicos. }\end{array}$ \\
\hline $\begin{array}{c}\text { Atuação/exper } \\
\text { iência }\end{array}$ & $\begin{array}{c}\text { Saberes da formação } \\
\text { profissional; Saberes } \\
\text { da experiência. }\end{array}$ & Saber atitudinal. & Saberes experienciais; & $\begin{array}{c}\text { Saberes da } \\
\text { experiência; }\end{array}$ \\
\hline $\begin{array}{c}\text { Conhecimento } \\
\text { /específicos }\end{array}$ & $\begin{array}{c}\text { Saberes das } \\
\text { disciplinas; }\end{array}$ & $\begin{array}{c}\text { Saber crítico- } \\
\text { contextual; Saber } \\
\text { específico; Saber } \\
\text { pedagógico; }\end{array}$ & $\begin{array}{c}\text { Saberes das Ciências da } \\
\text { Educação; Saberes } \\
\text { curriculares; }\end{array}$ & $\begin{array}{c}\text { Saberes do } \\
\text { conhecimento; }\end{array}$ \\
\hline
\end{tabular}

Quadro 1 Categorização dos saberes docentes Fonte: Elaborado pela autora

É possível perceber que, embora existam características próprias individuais, os autores seguem uma linha de entendimento semelhante. Todos defendem que tais saberes são necessários ao ensino e são construídos ou aprimorados ao longo da formação e carreira profissional. Além disso, as categorias contemplam aspectos aproximados do que cada autor aborda.

\subsection{MÉTODOS E METODOLOGIAS DE ENSINO}

Analisando a evolução das metodologias de ensino, Anastasiou (2001) faz um resgate histórico da universidade brasileira, com a abordagem de alguns elementos da trajetória metodológica, efetivada nos processos de ensino, ocorridos ao longo da existência da universidade no Brasil. Destacam-se na história a influência de modelos jesuíticos.

Os métodos de ensino adotados no modelo jesuítico, conforme Anastasiou (2001), desenvolviam-se basicamente em dois momentos fundamentais, primeiro a leitura de um texto e interpretação pelo professor, análise de palavras e comparação com outros autores e em um segundo momento, realizavam-se questionamentos entre alunos e professores. Aos alunos, cabia realizar anotações e resoluções de exercícios para fixação do conteúdo. A perspectiva do modelo jesuítico compreendeu o método escolástico ou parisiense.

O método escolástico conforme Anastasiou (2001, p.2) tinha por objetivo "a colocação exata e analítica dos temas a serem estudados, clareza nos conceitos e definições, argumentação precisa e sem digressões, expressão rigorosa, lógica e silogística, em latim”. Neste método, a sequência didática das atividades baseava-se na exposição, argumentações a 
favor e contrários e, a solução do mestre a respeito do assunto, assim, com tais características, esse método predominou em muitas universidades europeias, com destaque à Universidade de Paris onde se constituiu e se denominou método parisiense.

No método parisiense destaca-se a figura do professor como repassador do conteúdo, com aulas expositivas seguida de exercícios a serem resolvidos pelos alunos. A forma de avaliação, a aplicação de castigos, o controle rígido dentro e fora de sala de aula, o aluno passivo e obediente que memorizava ou decorava o conteúdo para as avaliações, eram características deste sistema marcado pela rigidez do processo de ensino-aprendizagem. Ainda hoje, muitos desses elementos estão presentes no cotidiano das salas de aula (ANASTASIOU, 2001).

Conforme Anastasiou (2001), os elementos do modelo francês-napoleônico surgiram no ensino superior brasileiro durante o Brasil colônia, e caracterizava-se pelo ensino profissionalizante, centrado nos cursos e faculdades. Metodologicamente, a relação professor/aluno/conhecimento era centralizado no professor como repassador do conteúdo e no estudo das obras clássicas da época. A aceitação passiva por parte dos alunos e a necessidade de memorização para realização das avaliações, eram fundamentais neste modelo.

Já a influência que a universidade brasileira recebeu do modelo alemão, ainda conforme a autora, modificou a estrutura até então rígida e centrada no repasse de conhecimento. Aqui, as metodologias do ensino se voltaram para a parceria entre alunos e professores, na realização de pesquisas cientificas como forma de construção do conhecimento, situações extremamente opostas ao modelo francês.

Conforme Anastasiou (2001, p.9), “experiências com novas formas de enfrentamento dos quadro teórico-práticos dos cursos de graduação vem sendo feitas, ainda que numericamente minoritárias", isto segundo a autora inclui a "construção coletiva de projetos pedagógicos institucionais e de cursos, revisões metodológicas na direção de um processo dialético de construção do conhecimento, evidenciando atividades de ensino com pesquisa", tais aspectos visam a formação profissional mais qualificada e atualizada.

Visões mais modernas trazidas pelos avanços da tecnologia que facilitou o acesso à informação e, o processo de internacionalização das culturas, tem mudado as concepções acerca do papel do professor. Com isso, métodos e metodologias de ensino devem atender a esta necessidade, e as técnicas de ensino aprimoradas constantemente (VEIGA, 2006). 
Para compreender e identificar os métodos e metodologias essenciais no processo educacional, é preciso antes entender os elementos específicos do processo de ensinoaprendizagem. De acordo com Kubo e Botomé (2005), o processo de ensino-aprendizagem é um sistema de interações comportamentais entre professores e alunos, pois há os processos comportamentais atribuídos como "ensinar" e "aprender". Além disso, os autores salientam que a interdependência desses dois conceitos é fundamental para compreender o que acontece, e seu entendimento e percepção constitui algo essencial para o desenvolvimento dos trabalhos de aprendizagem, de educação ou de ensino.

De acordo com a concepção de Veiga (2006), no processo de ensino é importante que o professor defina as estratégias e técnicas a serem utilizadas. Uma estratégia de ensino é uma abordagem adaptada pelo professor que determina o uso de informações, orienta a escolha dos recursos a serem utilizados, permite escolher os métodos para a consecução de objetivos específicos e compreende o processo de apresentação e aplicação dos conteúdos. Já as técnicas são componentes operacionais dos métodos de ensino, têm caráter instrumental uma vez que intermediam a relação entre professor e aluno, são favoráveis e necessárias no processo de ensino-aprendizagem.

Na visão de Nérice (1987), a metodologia do ensino inclui método e técnicas de ensino, cuja diferenciação não é muito clara. Pode-se dizer que o método efetiva-se por meio de técnicas de ensino que são utilizadas para alcançar os objetivos por ele instituídos. Desta forma, Nérice (1987, p.285) define método de ensino como um "conjunto de procedimentos lógica e psicologicamente ordenados" utilizados pelo professor a fim de "levar o educando a elaborar conhecimentos, adquirir técnicas ou habilidades e a incorporar atitudes e ideais". Já as técnicas de ensino são "destinadas a dirigir a aprendizagem do educando, porém, num setor limitado, particular, no estudo de um assunto, ou num setor particular de um método de ensino", portanto, o método de ensino é mais amplo que a técnica.

Os métodos e metodologias de ensino são destinados a efetivar o processo de ensino, podendo ser de forma individual, em grupo, coletiva ou socializada-individualizante. Com base nos pressupostos de Nérice (1987), elaborou-se um resumo, conforme Quadro 2, de alguns métodos de ensino, suas definições e características. 


\begin{tabular}{|c|c|c|}
\hline Descrição & Definição & Principais Métodos \\
\hline $\begin{array}{c}\text { Métodos de ensino } \\
\text { coletivo }\end{array}$ & $\begin{array}{c}\text { Consistem em proporcionar ensino a um grupo de } \\
\text { educandos, considerando-os em condições } \\
\text { pessoais de estudo equivalentes, e orientar os } \\
\text { trabalhos escolares com base na capacidade } \\
\text { média da classe. }\end{array}$ & $\begin{array}{c}\text { Expositivo; Expositivo misto; } \\
\text { Arguição*; Leitura; etc. }\end{array}$ \\
\hline $\begin{array}{c}\text { Métodos de ensino } \\
\text { em grupo }\end{array}$ & $\begin{array}{c}\text { Também compreendido como dinâmica de grupo, } \\
\text { dão ênfase à interação e cooperação dos } \\
\text { educandos, levando-os a enfrentar tarefas de } \\
\text { estudo em conjunto. }\end{array}$ & $\begin{array}{c}\text { Painel; Simpósio; Debate; } \\
\text { Discussão; etc. }\end{array}$ \\
$\begin{array}{c}\text { Métodos de ensino } \\
\text { individualizado }\end{array}$ & $\begin{array}{c}\text { Consistem em se dirigir diretamente a cada } \\
\text { educando, procurando atendê-lo em suas } \\
\text { condições pessoais de preparo, motivação e } \\
\text { possibilidades. }\end{array}$ & $\begin{array}{c}\text { Instrução personalizada*; Instrução } \\
\text { programada*; Estudo dirigido } \\
\text { individual; Estudo supervisionado*; } \\
\text { Tarefas dirigidas, Módulos } \\
\text { instrucionais*; etc. }\end{array}$ \\
\hline $\begin{array}{c}\text { Método de ensino } \\
\text { socializado- } \\
\text { individualizante }\end{array}$ & $\begin{array}{c}\text { Procura oferecer, durante o estudo de uma } \\
\text { mesma unidade, oportunidades de trabalho em } \\
\text { grupo e a seguir individual, visando formar o } \\
\text { cidadão consciente, que toma as suas decisões } \\
\text { com base no seu próprio raciocínio. }\end{array}$ & $\begin{array}{c}\text { Métodos mistos de trabalho } \\
\text { individual e em grupo. }\end{array}$ \\
\hline
\end{tabular}

Quadro 2 Métodos de ensino

Fonte: Elaborado com base em Nérice (1987)

* Essas contribuições que Nérice trouxe precisam hoje ser reorientadas, justamente pela exigência de metodologias que contemplem trabalhos coletivos, compartilhados, em rede, criativos, dentre outros.

Tanto os estudantes quanto a sociedade passaram e estão passando por significativas, grandes e paradigmáticas mudanças, e que por isso, as tradicionais formas de ensinar já não servem, ou não são tão eficientes como no passado, despertando a necessidade de aprimoramento dessas práticas docentes (VAILLANT; MARCELO, 2012).

Um fato importante no ensino é o planejamento, a definição de quais métodos serão utilizados para o desenvolvimento das atividades. Nesse contexto, Gil (2012, p. 94) reflete sobre a falta de criatividade com que muitos professores ainda planejam seus cursos "simplesmente seguem os capítulos de um livro-texto, sem considerar o que é realmente necessário que os alunos aprendam", além disso, o autor destaca que muitos professores também utilizam sempre os mesmos métodos de ensino e procedimentos de avaliação, não acompanhando assim as mudanças e evoluções que vêm ocorrendo.

\subsection{ESTUDOS CORRELATOS}

Os saberes dos professores foi tema do estudo de Miranda, Casa Nova e Cornacchione Júnior (2012), com o propósito de avaliar os saberes predominantes nos docentes percebidos como professores-referência pelos alunos de um curso de Graduação em Ciências Contábeis, de uma universidade pública brasileira. Embasados pelas discussões da literatura acerca de 
saberes, competências e conhecimentos necessários à docência e aqueles necessários ao ensino de contabilidade, verificou-se como resultado da pesquisa que as disciplinas responsáveis pela experiência mais significativa de aprendizagem no decorrer do curso, eram as percebidas como disciplinas base, tais como Contabilidade Básica, Intermediária e Avançada, e que apresentavam maior aplicação prática. As razões principais para escolha dos docentes de referência foram a didática ou metodologia de ensino adotadas pelo professor, atitudes e qualidades pessoais do professor.

Mazzioni (2006) estudou as estratégias utilizadas no processo de ensino-aprendizagem verificando a concepções de alunos graduandos do $7^{\circ}$ e $8^{\circ}$ períodos e professores de ciências contábeis, com o objetivo de compreender as estratégias de ensino-aprendizagem que eram mais significativas a partir das perspectivas dos alunos, relacionando com aquelas utilizadas pelos professores do curso de graduação em Ciências Contábeis. Verificou-se na pesquisa com os alunos que 40,76\% citaram a resolução de exercícios como o tipo de aula mais eficaz; $41,03 \%$ relatam que a aula expositiva é a estratégia de ensino mais utilizada pelos professores; e $35,91 \%$ indicaram que o data show é o recurso didático mais utilizado pelos docentes em sala de aula. Quanto à pesquisa com os docentes, observou-se que 35,29\% consideram a resolução de exercício como estratégia mais bem sucedida no processo de ensinoaprendizagem; $25,81 \%$ apontam para a aula expositiva como a principal estratégia; e 23,53\% indicam o quadro branco como o recurso didático mais utilizado.

Esta pesquisa apoia-se na de Mazzioni (2006) e busca verificar quais os métodos mais eficazes em relação à aprendizagem, e destes, quais vem sendo utilizados pelos professores na percepção dos alunos, além disso, será analisado a formação docente dos professores. A amostra analisada compreende alunos graduandos em Ciências Contábeis do $5^{\circ}$ ao $8^{\circ}$ período, a fim de expandir a amostra pesquisada.

O estilo de aprendizagem dos alunos foi alvo da pesquisa de Valente, Abib e Kusnik (2007), neste estudo aplicou-se o Teste Kolb para identificar os estilos de aprendizagem dos alunos e professores do curso de graduação em Ciências Contábeis da Universidade Estadual de Ponta Grossa (UEPG). Os resultados demonstraram que a maioria dos alunos pesquisados (53\%) concentrou-se no grupo "experimentação ativa", e os professores em sua maioria (45\%) mostraram predominância no estilo denominado "conceituação abstrata", demonstrando discrepância entre o modo de aprender com o de ensinar. Tais resultados indicam que grande parte dos docentes prefere ensinar por meio de conceitos e fundamentos, 
visando à produtividade e à competência, trabalhando as habilidades que consideram necessárias para que os alunos saibam como fazer as coisas. Os alunos em sua maioria, preferem aprender com professores que encorajam a aprendizagem experimental e a autodescoberta, e que procuram expandir os limites intelectuais dos alunos.

Nogueira e Bastos (2012), pesquisaram a forma pela qual professores e alunos de um curso de Administração, em uma Universidade particular na cidade de São Paulo, percebem as competências docentes com o objetivo de levantar, junto aos docentes, a indicação das competências no processo de ensino-aprendizagem e como estas são percebidas pelos discentes. Alguns dos principais resultados apontaram que há diferenças entre a percepção dos docentes e discentes principalmente sobre as competências docentes e as estratégias de ensino, e sobre o desenvolvimento de competências nos alunos. Com relação às Estratégias de Ensino, os professores relatam utilizar mais estudo de caso, aulas expositivas e leitura fora do ambiente de sala de aula e em classe, entretanto, na visão dos alunos, os professores utilizam forma menos constante essas estratégias.

\section{PROCEDIMENTOS METODOLÓGICOS}

A fim de verificar quais os métodos de ensino se mostram mais eficazes em relação à aprendizagem, na percepção dos alunos e, destes, quais têm sido mais utilizados pelos professores, realizou-se uma análise descritiva no que se refere aos objetivos, com abordagem quantitativa quanto ao problema, por meio de pesquisa de levantamento.

\subsection{POPULAÇÃO E AMOSTRA}

A população da pesquisa compreende 145 alunos regularmente matriculados do $5^{\circ}$ ao $8^{\circ}$ período do Curso de Graduação em Ciências Contábeis do Campus de Chapecó/SC da Universidade Comunitária da Região de Chapecó - Unochapecó e os 20 professores do Curso de Ciências Contábeis desta instituição de ensino. A escolha da Instituição de Ensino Superior deu-se pela acessibilidade para aplicação da pesquisa, e também pela significância desta IES no âmbito do ensino superior da região. Quanto aos professores, são aqueles vinculados ao curso de ciências contábeis.

O método de amostragem é intencional e não probabilístico, justifica-se por ser um estágio mais avançado do curso, nesta etapa há menores índices de desistência e, além disso, estes acadêmicos já possuem melhor discernimento para elencar quais os métodos mais 
eficazes para seu aprendizado. Desta forma, a amostra da pesquisa é representada pelos respondentes do instrumento de pesquisa, totalizando 95 acadêmicos e 17 professores.

\subsection{PROCEDIMENTOS DE COLETA DOS DADOS}

Os dados foram coletados no mês de março de 2014 e analisados com agrupamento de respostas similares por meio da aplicação da entropia de informação. Para a coleta dos dados com os alunos, elaborou-se um instrumento de pesquisa a partir do levantamento feito na literatura, com técnicas, métodos e recursos sugeridos para utilização em sala de aula, com o intuito do aluno respondente indicar sua percepção dos métodos mais eficazes para seu aprendizado, e destes, quais os professores têm utilizado para ministrar as aulas.

Além disso, elaborou-se um instrumento para a coleta de dados com os professores a fim de verificar a titulação e a formação docente. A aplicação destes instrumentos deu-se de forma presencial na Instituição de Ensino.

\subsection{PROCEDIMENTOS DE ANÁLISE DOS DADOS}

A fim de verificar as metodologias de ensino-aprendizagem realizou-se análise de conteúdo e também aplicou-se a entropia de informação. Para Bardin (1977, p. 42), a análise de conteúdo compreende diversas técnicas para analisar as informações com o intuito de “obter, por procedimentos, sistemáticos e objetivos de descrição do conteúdo das mensagens, indicadores (quantitativos ou não) que permitam a inferência de conhecimentos relativos às condições de produção/recepção [...] destas mensagens".

A entropia da informação conforme Zeleny (1982) é uma medida simples, porém importante, devido à quantidade de informações fornecidas com base em uma fonte de informação dada e, a fórmula do cálculo da entropia ocorre por meio de alguns passos predefinidos:

Sejam $d_{i}=\left(d_{i}^{1}, d_{i}^{2}, \ldots, d_{i}^{m}\right)$ os valores normalizados, em que: $d_{i}^{d^{k}}=\frac{x_{i}^{k}}{x_{i}^{*}}$, caracteriza $o$ conjunto $\mathrm{D}$, em termos do i-ésimo atributo. 
Encontra-se $\mathrm{D}_{\mathrm{i}}=\sum_{\mathrm{k}=1}^{\mathrm{m}} \mathrm{d}_{\mathrm{i}}^{\mathrm{k}} ; \mathrm{i}=1,2, \ldots, \mathrm{n}$

. Busca-se então a medida de entropia do contraste

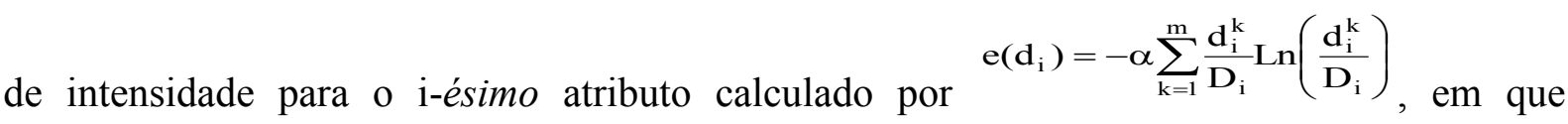
$\alpha=\frac{1}{\mathrm{e}_{\max }}>0 \quad$ e $\mathrm{e}_{\max }=\operatorname{Ln}(\mathrm{m})$. Observa-se ainda que $0 \leq \mathrm{d}_{\mathrm{i}}^{\mathrm{k}} \leq 1 \mathrm{e}^{\mathrm{d}_{\mathrm{i}}^{\mathrm{k}} \geq 0}$.

Caso todos os $d_{i}^{k}$ forem iguais para um dado $i$, então $\frac{d_{i}^{k}}{D_{i}}=\frac{1}{n}$ e e $\left(d_{i}\right)$ assume o valor máximo, isto é, $\mathrm{e}_{\max }=\mathrm{Ln}(\mathrm{m})$. Ao se fixar $\alpha=\frac{1}{\mathrm{e}_{\max }}$, determina-se $0 \leq \mathrm{e}\left(\mathrm{d}_{\mathrm{i}}\right) \leq 1$ para todos os $\mathrm{d}_{\mathrm{i}}{ }^{\prime} \mathrm{s}$. Essa normalização é necessária para efeito comparativo.

Dessa maneira, a entropia total de D é definida por: $E=\sum_{i=1}^{n} \mathrm{e}\left(\mathrm{d}_{\mathrm{i}}\right)$.

Quanto maior for e $\left(\mathrm{d}_{\mathrm{i}}\right)$ menor é a informação transmitida pelo i-ésimo atributo. Caso $\mathrm{e}\left(\mathrm{d}_{\mathrm{i}}\right)=\mathrm{e}_{\mathrm{max}}=\mathrm{Ln}(\mathrm{m})$, então o i-ésimo atributo não transmite informação e pode ser removida da análise decisória. Em virtude do peso $\tilde{\lambda}_{\mathrm{i}}$ ser inversamente relacionado a e $\left(\mathrm{d}_{\mathrm{i}}\right)$, usa-se 1-e $\left(\mathrm{d}_{\mathrm{i}}\right)$ ao invés de e $\left(\mathrm{d}_{\mathrm{i}}\right)$ e normaliza-se para assegurar que $0 \leq \tilde{\lambda}_{\mathrm{i}} \leq 1$ e $\mathrm{i}_{\mathrm{i}=1}^{\mathrm{n}} \tilde{\lambda}_{\mathrm{i}}=1$.

Assim, a entropia da informação pode ser representada por:

$$
\tilde{\lambda}_{\mathrm{i}}=\frac{1}{\mathrm{n}-\mathrm{E}}\left[1-\mathrm{e}\left(\mathrm{d}_{\mathrm{i}}\right)\right]=\frac{\left[1-\mathrm{e}\left(\mathrm{d}_{\mathrm{i}}\right)\right]}{\mathrm{n}-\mathrm{E}} \text {. }
$$

\section{ANÁLISE DOS DADOS}

Após a coleta tabulou-se os dados em uma planilha do Excel para obter os percentuais de resposta de cada item, paralelo a isso, elaborou-se o cálculo da entropia da informação das questões analisadas, com o intuito de verificar a variação de opiniões entre as respostas das questões conforme apresentado a seguir.

A Tabela 1 apresenta a percepção dos alunos referente aos métodos de ensino, quanto consideram eficaz para seu aprendizado. De acordo com Veiga (2006) os métodos e metodologias de ensino devem atender a necessidade de aprendizado dos alunos, e suas técnicas devem ser aprimoradas constantemente. 
Tabela 1 Percepção dos alunos da importância dos métodos de ensino para seu aprendizado

\begin{tabular}{|c|c|c|c|c|c|c|}
\hline \multirow[b]{2}{*}{$\mathbf{N}^{\mathbf{o}}$} & \multirow[b]{2}{*}{ Técnicas/Métodos } & \multicolumn{5}{|c|}{ Importância para o aprendizado } \\
\hline & & Muito Eficaz & Eficaz & $\begin{array}{c}\text { Não } \\
\text { Eficaz }\end{array}$ & Entropia $e\left(d_{i}\right)$ & Peso $\tilde{\lambda}_{\mathrm{i}}$ \\
\hline$\overline{1}$ & Aulas expositivas (teórica) & $39 \%$ & $59 \%$ & $2 \%$ & 0,9946 & 0,0776 \\
\hline 2 & Aulas mistas (teórica e prática) & $77 \%$ & $23 \%$ & $0 \%$ & 0,9972 & 0,0406 \\
\hline 3 & Seminários/Debates & $22 \%$ & $66 \%$ & $12 \%$ & 0,9916 & 0,1199 \\
\hline 4 & Resolução de exercícios & $84 \%$ & $16 \%$ & $0 \%$ & 0,9980 & 0,0282 \\
\hline 5 & Estudos de Casos & $41 \%$ & $55 \%$ & $4 \%$ & 0,9940 & 0,0853 \\
\hline 6 & Dinâmicas & $36 \%$ & $47 \%$ & $17 \%$ & 0,9879 & 0,1722 \\
\hline 7 & Pesquisas extra classe & $19 \%$ & $65 \%$ & $16 \%$ & 0,9908 & 0,1315 \\
\hline 8 & Trabalhos em grupo & $26 \%$ & $65 \%$ & $8 \%$ & 0,9923 & 0,1092 \\
\hline 9 & Trabalhos individuais & $41 \%$ & $54 \%$ & $5 \%$ & 0,9930 & 0,0992 \\
\hline 10 & Provas & $34 \%$ & $55 \%$ & $12 \%$ & 0,9904 & 0,1362 \\
\hline \multicolumn{5}{|c|}{ Total } & 9,9299 & 1,0000 \\
\hline
\end{tabular}

Fonte: Dados da pesquisa

Conforme Zeleny (1982), quanto maior for o ${ }^{e\left(d_{i}\right)}$, menor será a informação transmitida por ele, ou seja, o grau da entropia será maior quanto mais próximo do zero o $e\left(d_{i}\right)$ for. Nesse sentido, após calcular o peso $\tilde{\lambda}_{\mathrm{i}}$ de cada questão em relação ao total do grupo (10 questões), verifica-se que a questão que apresentou maior $e\left(d_{i}\right)$ é a que retém a menor entropia e vice-versa. Percebe-se que o maior $e\left(d_{i}\right)=0,9980$ e o menor $\tilde{\lambda}_{\mathrm{i}}=0,0282$ está para a questão 4 relacionada a resolução de exercícios, isso significa que essa questão apresenta a menor informação transmitida, ou seja, a menor diversidade de opiniões entre as respostas, demonstrando que a maioria dos aluno possuem opiniões semelhantes sobre essa questão, $84 \%$ deles consideram este método ou técnica de ensino como muito eficaz para seu aprendizado.

A questão sobre as dinâmicas como método de ensino é a que apresenta o menor $e\left(d_{i}\right)$ $=0,9879$, consequentemente resultando no maior peso, $\tilde{\lambda}_{i}=0,1722$, ou seja, esta questão foi a que apresentou maior diversidade de opiniões entre as respostas dos alunos, 36\% consideraram muito eficaz, $47 \%$ eficaz e $17 \%$ não eficaz. Outro método/técnica de ensino que também vale a pena destacar são as aulas mistas (teórica e prática), que na percepção de $77 \%$ dos alunos é muito eficaz para seu aprendizado.

$\mathrm{Na}$ Tabela 2, apresenta-se a percepção dos alunos referente às técnicas e métodos de ensino em relação a quanto os professores têm utilizado para o ensino. 
Tabela 2 Percepção dos alunos de quanto o professor utiliza os métodos para o ensino

\begin{tabular}{|c|c|c|c|c|c|c|}
\hline \multirow[b]{2}{*}{$\mathbf{N}^{\mathbf{0}}$} & \multirow[b]{2}{*}{ Técnicas/Métodos } & \multicolumn{5}{|c|}{ Quanto o professor utiliza para o ensino } \\
\hline & & Utiliza Muito & $\begin{array}{l}\text { Utiliza } \\
\text { Pouco }\end{array}$ & Não Utiliza & Entropia $^{e\left(d_{i}\right)}$ & Peso $\tilde{\lambda}_{\mathrm{i}}$ \\
\hline 1 & Aulas expositivas (teórica) & $87 \%$ & $13 \%$ & $0 \%$ & 0,9984 & 0,0254 \\
\hline 2 & Aulas mistas (teórica e prática) & $48 \%$ & $51 \%$ & $1 \%$ & 0,9950 & 0,0777 \\
\hline 3 & Seminários/Debates & $7 \%$ & $75 \%$ & $18 \%$ & 0,9921 & 0,1235 \\
\hline 4 & Resolução de exercícios & $65 \%$ & $34 \%$ & $1 \%$ & 0,9958 & 0,0663 \\
\hline 5 & Estudos de Casos & $18 \%$ & $69 \%$ & $13 \%$ & 0,9914 & 0,1352 \\
\hline 6 & Dinâmicas & $8 \%$ & $51 \%$ & $41 \%$ & 0,9845 & 0,2427 \\
\hline 7 & Pesquisas extra classe & $31 \%$ & $59 \%$ & $11 \%$ & 0,9919 & 0,1264 \\
\hline 8 & Trabalhos em grupo & $52 \%$ & $48 \%$ & $0 \%$ & 0,9956 & 0,0695 \\
\hline 9 & Trabalhos individuais & $51 \%$ & $45 \%$ & $4 \%$ & 0,9935 & 0,1013 \\
\hline 10 & Provas & $89 \%$ & $9 \%$ & $1 \%$ & 0,9980 & 0,0320 \\
\hline \multicolumn{5}{|c|}{ Total } & 9,9362 & 1,0000 \\
\hline
\end{tabular}

Fonte: Dados da pesquisa

Do mesmo modo em que se apresenta a importância dos métodos e técnicas para o aprendizado, se encontra a percepção dos alunos de quanto os professores têm utilizado para o ensino. Conforme a Tabela 2 verifica-se que o maior $e\left(d_{i}\right)=0,9988$ e o menor $\tilde{\lambda}_{\mathrm{i}}=0,0254$ está para a questão 1, aulas expositivas (teóricas). Isso significa que essa questão apresenta a menor informação transmitida, ou seja, a menor diversidade de opiniões entre as respostas, demonstrando que a maioria dos alunos possuem opiniões semelhantes sobre essa questão, $87 \%$ consideram este método de ensino como a que os professores mais utilizam para o ensino. Se comparado esse resultado com a Tabela 1, verifica-se que apenas $39 \%$ dos alunos consideram esse método ou técnica como muito eficaz para o seu aprendizado.

A questão 6 que se refere às dinâmicas como método de ensino, assim como visto na Tabela 1, é a que apresenta o menor $e\left(d_{i}\right)=0,9845$, resultando no maior peso, $\tilde{\lambda}_{i}=0,2427$. Esta foi a questão que apresentou maior diversidade de opiniões entre as respostas dos alunos, apenas $8 \%$ consideraram que os professores utilizam muito, $51 \%$ que utilizam pouco e $17 \%$ que os professores não utilizam. As provas foram consideradas por $89 \%$ dos alunos como muito utilizadas pelos professores, quando comparado com sua importância, disposto na Tabela 1, 34\% dos alunos consideraram muito eficaz para seu aprendizado, $55 \%$ eficaz e $12 \%$ como não eficaz.

A Tabela 3 contempla a percepção dos alunos quanto a importância dos recursos para seu aprendizado. 
Tabela 3 Percepção dos alunos quanto a importância dos recursos para seu aprendizado

\begin{tabular}{|c|c|c|c|c|c|c|}
\hline \multirow[b]{2}{*}{$\mathbf{N}^{\mathbf{o}}$} & \multirow[b]{2}{*}{ Recursos } & \multicolumn{5}{|c|}{ Importância para o aprendizado } \\
\hline & & Muito eficaz & Importante & Não eficaz & Entropia $^{e\left(d_{i}\right)}$ & Peso $\tilde{\lambda}_{i}$ \\
\hline 1 & PowerPoint (data show) & $49 \%$ & $44 \%$ & $6 \%$ & 0,9925 & 0,1451 \\
\hline 2 & Quadro & $44 \%$ & $52 \%$ & $4 \%$ & 0,9935 & 0,1260 \\
\hline 3 & Filmes/Vídeos & $22 \%$ & $62 \%$ & $16 \%$ & 0,9899 & 0,1966 \\
\hline 4 & Uso de laboratórios & $38 \%$ & $56 \%$ & $6 \%$ & 0,9926 & 0,1434 \\
\hline 5 & Visitas a empresas & $57 \%$ & $38 \%$ & $5 \%$ & 0,9926 & 0,1429 \\
\hline 6 & Apostilas/Livros & $58 \%$ & $40 \%$ & $2 \%$ & 0,9948 & 0,1012 \\
\hline 7 & Leituras complementares & $42 \%$ & $52 \%$ & $6 \%$ & 0,9925 & 0,1448 \\
\hline \multicolumn{5}{|c|}{ Total } & 6,9484 & 1,0000 \\
\hline
\end{tabular}

Fonte: Dados da pesquisa

Após calcular o peso $\lambda_{i}$ de cada questão em relação ao total do grupo (7 questões), verifica-se que a questão que apresentou maior $e\left(d_{i}\right)$ é a que retém a menor entropia e viceversa. De acordo com os dados dispostos na Tabela 3 em relação à percepção dos alunos quanto a importância dos recursos para seu aprendizado, observa-se que o maior ${ }^{e\left(d_{i}\right)}=$ 0,9948 e o menor $\lambda_{i}=0,1012$ refere-se à questão 6 relacionada ao uso de apostilas/livros, isso significa que essa questão apresenta a menor informação transmitida, ou seja, a menor diversidade de opiniões entre as respostas, demonstrando que a maioria dos aluno possuem opiniões semelhantes sobre essa questão. Mesmo que os percentuais estejam equilibrados, $58 \%$ dos alunos consideram a utilização de livros e apostilas como o recurso que é muito eficaz para seu aprendizado.

A questão 3, que contempla o recurso filmes/vídeos e técnica de ensino é a que apresenta o menor $e\left(d_{i}\right)=0,9899$, consequentemente resultando no maior peso, $\tilde{\lambda}_{\mathrm{i}}=0,1966$ ou seja, esta questão apresentou maior diversidade de opiniões entre as respostas dos alunos, $22 \%$ consideraram muito eficaz, $62 \%$ eficaz e $16 \%$ não eficaz.

Na Tabela 4 apresenta-se a percepção dos alunos referente aos recursos, quanto os professores têm utilizado para o ensino. 
Tabela 4 Percepção dos alunos de quanto o professor utiliza os recursos para o ensino

\begin{tabular}{c|c|ccc|cc}
\hline \multirow{2}{*}{$\mathbf{N}^{\mathbf{*}}$} & \multirow{2}{*}{ Recursos } & \multicolumn{5}{|c}{ Quanto o professor utiliza para o ensino } \\
\cline { 2 - 6 } & & $\begin{array}{c}\text { Utiliza } \\
\text { Muito }\end{array}$ & $\begin{array}{c}\text { Utiliza } \\
\text { Pouco }\end{array}$ & $\begin{array}{c}\text { Não } \\
\text { Utiliza }\end{array}$ & Entropia $e\left(d_{i}\right)$ & $\tilde{\lambda}_{\mathrm{i}}$ \\
\hline 1 & PowerPoint (data show) & $84 \%$ & $14 \%$ & $2 \%$ & 0,9963 & 0,0618 \\
2 & Quadro & $60 \%$ & $40 \%$ & $0 \%$ & 0,9950 & 0,0832 \\
3 & Filmes/Vídeos & $6 \%$ & $53 \%$ & $41 \%$ & 0,9855 & 0,2411 \\
4 & Uso de laboratórios & $6 \%$ & $64 \%$ & $29 \%$ & 0,9891 & 0,1805 \\
5 & Visitas a empresas & $4 \%$ & $46 \%$ & $49 \%$ & 0,9851 & 0,2478 \\
6 & Apostilas/Livros & $65 \%$ & $35 \%$ & $0 \%$ & 0,9956 & 0,0724 \\
7 & Leituras complementares & $29 \%$ & $64 \%$ & $6 \%$ & 0,9932 & 0,1132 \\
\hline \multicolumn{7}{l}{ Total } \\
\hline
\end{tabular}

Fonte: Dados da pesquisa

Assim como foi apresentado a importância dos recursos para o aprendizado, analisa-se a percepção dos alunos de quanto os professores têm utilizado tais recursos para o ensino. Conforme a Tabela 4 , verifica-se que o maior $e\left(d_{i}\right)=0,9963$ e consequentemente o menor $\tilde{\lambda}_{\mathrm{i}}=0,0618$ está para a questão 1 , recurso de PowerPoint (data show), isso significa que essa questão apresenta a menor informação transmitida, ou seja, a menor diversidade de opiniões entre as respostas, demonstrando que a maioria dos aluno possuem opiniões semelhantes sobre essa questão, $84 \%$ consideram este recurso como o mais utilizado pelos professores para o ensino. No entanto, se comparado este resultado com a Tabela 3, verifica-se que apenas $49 \%$ dos alunos consideram este como um recurso muito eficaz para o seu aprendizado.

O recuso apostilas/livros foi considerado por $58 \%$ dos alunos como um recurso muito eficaz para o aprendizado, conforme demonstrado anteriormente na Tabela $3 . \mathrm{Na}$ análise da utilização disposto na Tabela 4, os alunos citam este recurso como o segundo mais utilizado pelos professores, $65 \%$ consideraram a opção "utiliza muito".

A questão 5, que se refere à visitas a empresas, é a que apresenta o menor ${ }^{e\left(d_{i}\right)}=$ 0,9851 , resultando no maior peso, $\lambda_{i}=0,2478$, esta questão foi a que apresentou maior diversidade de opiniões entre as respostas dos alunos, somente $4 \%$ consideraram que os professores utilizam muito, $46 \%$ que utilizam pouco e $49 \%$ que os professores não utilizam.

Nogueira e Bastos (2012) em seu estudo verificaram que na visão dos alunos, os professores utilizam de forma menos constante estratégia de ensino como leituras fora do ambiente de sala de aula e em classe, o que corrobora com os achados nesta pesquisa. 
Conforme a Tabela 4, verificou-se que $64 \%$ dos alunos citam as leituras complementares como um recurso pouco utilizado pelos professores.

Após a análise das respostas dos alunos com a entropia de informação, apresenta-se a análise da titulação dos professores e formação docente, verificou-se as frequências absolutas e relativas das respostas. A Tabela 5 contempla a titulação acadêmica dos professores.

Tabela 5 Titulação acadêmica dos professores

\begin{tabular}{lc|c|c}
\hline & Titulação acadêmica & $\begin{array}{c}\text { Frequência } \\
\text { absoluta }\end{array}$ & $\begin{array}{c}\text { Frequência } \\
\text { relativa }\end{array}$ \\
\hline Pós - Doutorado & 0 & $0 \%$ \\
Doutorado & 1 & $6 \%$ & $59 \%$ \\
Mestrado & & 10 & $35 \%$ \\
Especialização & & 6 & $0 \%$ \\
Graduação & Total & 17 & $100 \%$ \\
\hline
\end{tabular}

Fonte: Dados da pesquisa

De acordo com os dados apresentados na Tabela 5 a maior parte dos professores possuem a titulação de mestre sendo $59 \%$, com especialização são $35 \%$ e, com doutorado apenas 1 professor, o que representa $6 \%$ da amostra. Nenhum deles possui pós-doutorado e também nenhum deles é somente graduado.

Verificou-se também a formação docente dos professores, conforme disposto na Tabela 6. Conforme Tardif (2002), os saberes docentes são adquiridos por meio de processo progressivo, iniciado ainda quando o professor está em sala de aula na condição de aluno em formação. Tal processo de formação é importante para o professor adquirir habilidades para o ensino.

Tabela 6 Formação docente dos professores

\begin{tabular}{l|c|c}
\hline \multicolumn{1}{c|}{ Formação docente } & $\begin{array}{c}\text { Frequência } \\
\text { absoluta }\end{array}$ & $\begin{array}{c}\text { Frequência } \\
\text { relativa }\end{array}$ \\
\hline Disciplina específica de metodologia do ensino durante o processo de formação & 17 & $100 \%$ \\
Estágio docente ou supervisionado & 5 & $29 \%$ \\
Cursos na própria instituição - Ciclos docentes & 6 & $35 \%$ \\
Cursos na própria instituição - Palestras & 1 & $6 \%$ \\
Outros - Especialização em docência no ensino superior & 3 & $18 \%$ \\
\hline
\end{tabular}

Fonte: Dados da pesquisa

De acordo com os dados dispostos na Tabela 6, verifica-se que $100 \%$ dos professores tiveram em sua formação uma disciplina específica de metodologia do ensino. A segunda maior frequência de respostas, é em relação aos cursos na própria instituição, $35 \%$ dos 
professores afirmaram participar de ciclos docentes, que são eventos de capacitação que ocorrem semestralmente na instituição de ensino.

Além disso, 29\% dos professores afirmaram ter participado de estágio docente ou supervisionado em seu processo de formação. Na concepção de Veiga (2006) os estágios orientados são experiências interessantes em programas de formação docente.

Dos 17 professores respondentes, 3 deles possuem curso de especialização em docência no ensino superior, o que representa $18 \%$ da amostra. Uma resposta foi obtida quanto a participação em palestras oferecidas pela própria instituição de ensino, porém, sem apontar a especificidade desta palestra.

\section{CONSIDERAÇÕES FINAIS}

O estudo teve como objetivo verificar quais os métodos de ensino se mostram mais eficazes em relação à aprendizagem, na percepção dos alunos e, destes, quais têm sido mais utilizados pelos professores. Para atender a este objetivo, aplicou-se a entropia da informação, que possibilitou a percepção da diversidade de opiniões nas respostas dos alunos respondentes, para assim observar os métodos, técnica e recursos que consideram mais eficazes para seu aprendizado e também, o que consideram que os professores têm mais utilizado para o ensino.

Quanto a importância das técnicas e métodos de ensino para seu aprendizado, a maioria dos alunos possuem opiniões semelhantes, $84 \%$ consideram a resolução de exercício como muito eficaz, demonstrando que sua aplicação é eficaz para seu aprendizado. As aulas mistas (teórica e prática) foram o segundo método ou técnica de ensino com mais concentração de resposta, $77 \%$ dos alunos a consideraram como "muito eficaz".

Em relação a percepção dos alunos de quanto o professor utiliza as técnicas e métodos para o ensino, as aulas expositivas (teóricas) tiveram a menor diversidade de opiniões entre as respostas, $87 \%$ dos alunos possuem opiniões semelhantes considerando este método ou técnica de ensino como a que os professores mais utilizam. Quando comparado este resultado à importância dada pelos alunos, verifica-se que apenas 39\% dos alunos consideram este método ou técnica como muito eficaz para o seu aprendizado.

Tais resultados corroboram com Mazzioni (2006), que em seu estudo verificou que a maioria dos alunos consideram a resolução de exercícios como o tipo de aula mais eficaz para seu aprendizado. Também encontrou que a aula expositiva foi a estratégia de ensino que os 
alunos consideraram como a mais utilizada pelos professores. No entanto, os resultados encontrados vão de encontro aos verificados por Nogueira e Bastos (2012), que na visão dos alunos, a estratégia de ensino denominada aulas expositivas era utilizada de forma menos constante pelos professores.

Vale destacar que as provas foram consideradas por $89 \%$ dos alunos como muito utilizadas pelos professores, quando comparado com sua importância, somente 34\% consideraram muito eficaz para seu aprendizado, $55 \%$ eficaz e $12 \%$ como não eficaz.

No que tange aos recursos, verificou-se uma distribuição mais equilibrada da opinião dos alunos, mesmo assim, 58\% consideram a utilização de livros e apostilas como um recurso muito eficaz, sendo assim eficaz para seu aprendizado. Já em relação a quanto os professores utilizam os recursos para o ensino, $84 \%$ dos alunos consideraram o PowerPoint (data show) como muito utilizado, corroborando o estudo de Mazzioni (2006). Se comparado este resultado com a importância atribuída pelos alunos, verifica-se que apenas $49 \%$ dos alunos consideram este como um recurso muito eficaz para seu aprendizado.

Com base nas análises realizadas, verificou-se que não houve convergência do que os alunos consideram mais eficaz para seu aprendizado, com o que na percepção deles os professores têm mais utilizado para o ensino.

Outra análise referiu-se a titulação e formação docente dos professores. Quanto a titulação, foi possível observar que a maior parte dos professores possuem a titulação de mestre, correspondeu a 59\%, com o título de especialista são $35 \%$ e com doutorado apenas 1 professor. No que se refere a formação docente, 100\% dos professores tiveram em sua formação uma disciplina específica de metodologia do ensino, 35\% participaram ou participam de ciclos docentes oferecidos pela própria instituição de ensino e $29 \%$ tiveram em sua formação estágio docente ou supervisionado.

Se verificada a formação docente, pressupõem-se que os professores possuem conhecimentos das metodologias, técnicas e recursos que são necessários ao ensino, porém, verifica-se a necessidade de atentarem-se ao que os alunos consideram eficaz para seu aprendizado, para assim, melhorar o processo de ensino. Os resultados obtidos neste estudo sugerem a necessidade dos professores atentarem-se aos métodos de ensino que são mais eficazes para a aprendizagem dos alunos, para assim melhorar a relação entre ensinoaprendizagem. 
Uma limitação do estudo é em relação aos resultados obtidos, pois a pesquisa se limitou ao estudo deste público alvo, portanto, contempla única e exclusivamente o olhar e a percepção do aluno acerca dos métodos, técnicas ou metodologias mais eficazes para seu aprendizado. Para pesquisa futuras, sugere-se a aplicação deste método comparando diferentes instituições de ensino, a fim de verificar se os resultados encontrados serão corroborados pelos resultados obtidos neste estudo.

\section{REFERÊNCIAS}

ANASTASIOU, L. G. C. Metodologia de Ensino na Universidade Brasileira: elementos de uma trajetória. Campinas: Papirus, 2001.

BARDIN L. Análise de conteúdo. Ed. 70, Lisboa, 1977.

CALDEIRA, A. M. S. A apropriação e construção do saber docente e a prática cotidiana. Cadernos de Pesquisa, v. 95, 1995.

CANTERLE, N. M. G.; FAVARETTO, F. Proposta de um modelo referencial de gestão de indicadores de qualidade na instituição universitária. Ensaio, v. 16, n. 60, p. 393-412, 2008.

CUNHA, E. R. Os saberes docentes ou saberes dos professores. Revista Cocar, v. 1, p. 31 39, 2007.

GAUTHIER, C.; MARTINEAU, S.; DESBIENS, J.-F.; MALO, A. e SIMARD, D. Por uma teoria da pedagogia: pesquisas contemporâneas sobre o saber docente. Editora Unijuí, 1998.

GIL, A. C. Didática do Ensino Superior. São Paulo: Atlas, 2012.

KUBO, O. M.; BOTOMÉ, S. P. Ensino-aprendizagem: uma interação entre dois processos comportamentais. Interação em Psicologia, v. 5, n. 1, 2005.

MAZZIONI, S. As estratégias utilizadas no processo de ensino-aprendizagem: concepções de alunos e professores de ciências contábeis. Chapecó, Unochapecó, 2006.

MIRANDA, G. J.; NOVA, S. P. C. C.; CORNACHIONE JÚNIOR, E. B. Os segredos dos professores-referência no ensino de contabilidade. Anais... In: $11^{\circ}$ Congresso USP de Controladoria e Contabilidade. São Paulo/SP. 2012.

MIRANDA, C. M. S; DOMINGUES, M. J. C. de S. Razões para escolha de uma IES: uma abordagem sobre o perfil socioeconômico de alunos interessados em cursar administração. ENANGRAD, v. 17, p. 67-70, 2006.

NÉRICE, I. G. Didática geral dinâmica. 10 ed., São Paulo: Atlas, 1987. 
NOGUEIRA, A. J. F. M.; BASTOS, F. C. Formação em Administração: O Gap de Competências Entre Alunos e Professores. REGE - Revista de Gestão, v. 19, n. 2, 2012.

NUNES, C. M. F. Saberes docentes e formação de professores: um breve panorama da pesquisa brasileira. Educação \& Sociedade, v. 22, n. 74, p. 27-42, 2001.

PIMENTA, S. G. Formação de professores-saberes da docência e identidade do professor. Nuances: Estudos sobre Educação, v. 3, n. 3, 1997.

SAVIANI, D. Os saberes implicados na formação do educador. Formação do educador: dever do Estado, tarefa da Universidade. São Paulo: Unesp, 1996.

TARDIF, M.; LESSARD, C.; LAHAYE, L. Os professores face ao saber - esboço de uma problemática do saber docente. Teoria \& Educação, Porto Alegre, n. 4, 1991.

TARDIF, M. Saberes profissionais dos professores e conhecimentos universitários. Revista brasileira de educação, v. 13, n. 5, 2000.

, M. Saberes docentes e formação profissional. Rio de Janeiro: Vozes, 2002.

VAILLANT, D.; MARCELO, C. Ensinando a ensinar. As quatro etapas de uma aprendizagem. Curitiba: Editora da Universidades Tecnológica Federal do Paraná, 2012.

VALENTE, N. T. Z.; KUSNIK, L. F.; ABIB, D. B. Análise dos estilos de aprendizagem dos alunos e professores do curso de graduação em ciências contábeis de uma universidade pública do estado do Paraná com a aplicação do inventário de David Kolb. Contabilidade Vista \& Revista, v. 18, n. 1, p. 51-74, 2007.

VEIGA, I. P. A. Técnicas de ensino: novos tempos, novas configurações. Papirus Editora, 2006.

ZELENY, M. Multiple criteria decision making. New York: McGraw-Hill, 1982. 